\title{
Effectiveness of Air Curtains as Thermal and Smoke Barrier Against High Gradients of Flow Parameters
}

\author{
M. A. M. S. Shoshe and M. A. Rahman \\ Bangladesh University of Engineering and Technology \\ Dhaka-1000, Dhaka, Bangladesh \\ shoshe1239@gmail.com; ashiqurrahman@me.buet.ac.bd
}

\begin{abstract}
This study aims to investigate air curtains as an effective thermal and aerosol barrier against high gradient of flow parameters generated by a typical fire incident. The numerical investigations are conducted by solving Navier-Stokes equations in Fire Dynamics Simulator (FDS). A clothing store of $12 \mathrm{~m}^{2}$ floor area with a fire of $1528 \mathrm{~kW} / \mathrm{m}^{2}$ heat release rate per unit area (HRRPUA), at the furthest corner from the door, is considered as the source of high thermal and pressure gradients inside the store. The only means of ventilation for the current study, is an air curtain of $0.91 \mathrm{~m}$ length placed at the door at $2.13 \mathrm{~m}$ height from the floor. The air curtain's injection velocity, injection angle, flow rate and cross-sectional area of the flow channel are systematically varied for optimum sealing performance. The change in temperature profile and aerosol particle concentration with and without air curtain, and air curtain effectiveness $E$, are measured. Result suggests, the injection velocity and injection angle are the key parameters in preventing the heat and mass transfer across air curtains. The twin jet design, a commercially available feature for air curtains, is found to be less effective up to pitch ratio of 4 compared to that of a single jet design for restraining heat and mass transfer.
\end{abstract}

Keywords: FDS, Shopping mall fire, Air curtain, PyroSim, Smoke barrier.

\section{Introduction}

Confining fire generated smoke and toxic gases at the source of fire can play a lifesaving role on the evacuees. Primary cause of death in building fires is inhalation of toxic smoke and subsequent asphyxiation [1,2]. Fire resistant doors, fire resistant walls and smoke control systems are traditionally used to confine the heat and smoke propagation in case of a fire incident. The application of fire doors or any other solid obstruction can have negative impact on identifying the proper escape route thus, could hamper the evacuation at early stages of fire. Moreover, application of solid obstructions to control smoke movement may not be practical in many situations like in a shopping mall corridor or a road tunnel. The introduction of aerodynamic sealing might be more appropriate for heat and smoke confinement in channels with high personal load. Air curtains hence can be a viable alternative to fire doors and other solid obstructions as it will not impair visibility and manoeuvrability in the installed space. Researchers used air curtains for sealing heat and mass transfer [3], odour and contaminant dispersion [4], and smoke confinement in case of tunnel fire [2, 5] successfully. Use of an opposite double jet air curtain proved not only to be effective in protecting staircase, an important region during evacuation, but also drive away the fire generated smoke from the channel in case of a building fire [6]. For an air curtain with momentum ratio $R=10$, an injection angle of $30^{\circ}$ inclined to the source was reported optimum for tunnel fire [7].

From the above discussion, it can be concluded that, air curtains can be used to confine the heat and smoke at fire source in case of a fire incident. As fire incidents in Bangladesh are frequent and devastating, installing air curtains at shop doors of shopping malls, especially in context of Dhaka, can be beneficial in many ways. There were at least 18,048 fire incidents from July 2016 to June 2017 in Bangladesh, and statistics shows 17\% of these included shopping malls [8]. Suggestions regarding the use of fire doors, fire screens or any other solid obstruction at shop front, as a preventive measure to minimize the devastation in case of a fire hazard, will not be practical for business for reason described earlier. On the other hand, a large number of traditional shopping malls in Bangladesh do not have central air conditioning system hence, aiming for better business, shop owners use split AC inside the shops, for thermal comfort of customers. Thus, air curtains can reduce the energy consumption and be a viable option to otherwise inadequate or absent firefighting equipment in these shopping malls. It will also provide easy access to shop insides for customers through the open door. 


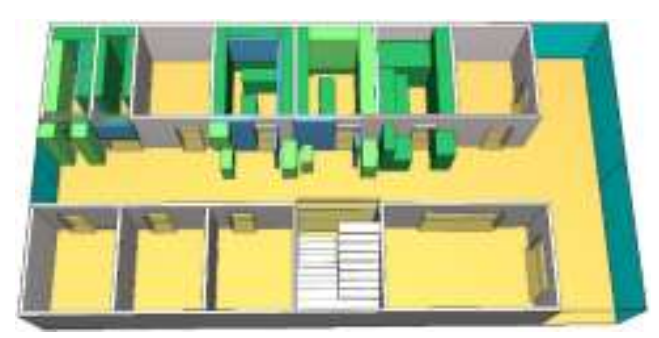

Fig. 1: Numerical model of a section from Gulshan DCC market, Dhaka, Bangladesh, investigated in FDS.

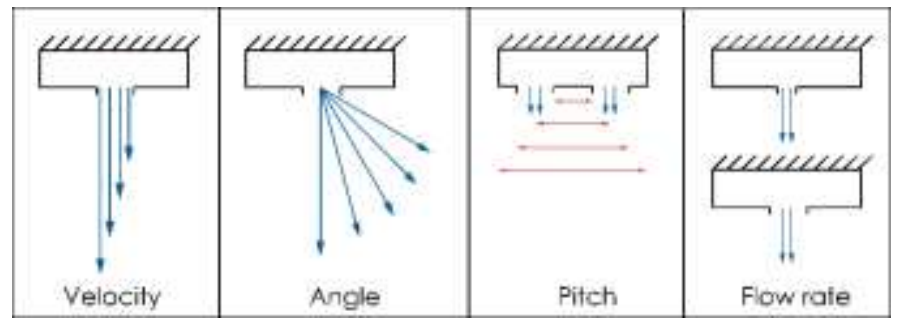

Fig. 2: Schematics of air curtain's parametric variations.

This paper thus, numerically investigates air curtain's sealing ability against high gradients of pressure and flow velocity generated in case of a typical shopping mall fire in context of Bangladesh. Air curtain's injection velocity, injection angle, flow rate and pitch ratio of flow channel were systematically varied to obtain the highest possible effectiveness against the heat and smoke transfer.

\section{Simulation Methodology}

\subsection{Governing equations}

The numerical studies were conducted in PyroSim (version 2018.3.1210) from Thunderhead Engineering. PyroSim is a graphical user interface (GUI) for Fire Dynamics Simulator FDS, (version 6.7.0 released on June 20, 2018). FDS is a Large Eddy Simulation (LES) code developed by the National Institute of Standards and Technology (NIST), which is a widely used fire simulation tool. FDS solves Navier-Stokes equations with low Mach number approximation. This approximation filters out acoustic waves and allows large variations in temperature and density, suitable for low speed, thermal convective processes. Turbulence modelling was performed with LES, and it is second order accurate in space and time. The LES momentum equation with Favre filter and subgrid-scale (SGS) stress is as follows in Eqs. (1),

$$
\frac{\partial \bar{\rho} \widetilde{u_{l}}}{\partial t}+\frac{\partial}{\partial x_{j}}\left(\bar{\rho} \widetilde{u_{l}} \widetilde{u_{J}}\right)=-\frac{\partial \bar{\rho}}{\partial x_{i}}-\frac{\partial \overline{\tau_{l j}}}{\partial x_{j}}-\frac{\partial \tau_{i j}^{s g s}}{\partial x_{j}}+\bar{\rho} g_{i}+\overline{f_{d, l}}+\overline{\dot{m}_{b}^{m}} \widetilde{u_{b, l}}
$$

By dot product of the LES momentum equation with the resolved velocity vector, the transport equation for the resolved kinetic energy per unit mass is derived. FDS 6.7.0 uses a variation of Deardorff's model for computing the turbulent viscosity, $\mu_{t}$ defined as in Eqs. (2). Where $\bar{u}$ is the average value of $u$ at the grid cell center and $\hat{\bar{u}}$ is a weighted average of $u$ over the adjacent cells. The thermal conductivity $k_{t}$, and mass diffusivity $(\rho D)_{t}$, are related to the turbulent viscosity by constant turbulent Prandtl number $\operatorname{Pr}_{t}$ and constant turbulent $S$ chmidt number $\mathrm{Sc}_{t}$.

$$
\mu_{t}=\rho C_{v} \Delta \sqrt{k_{s g s}} ; k_{s g s}=\frac{1}{2}\left((\bar{u}-\hat{u})^{2}+(\bar{v}-\hat{v})^{2}+(\bar{w}-\widehat{\bar{w}})^{2}\right) ; k_{t}=\frac{\mu_{t} c_{p}}{P r_{t}} ; \quad(\rho D)_{t}=\frac{\mu_{t}}{S c_{t}}
$$

\subsection{The Physical Model and Air Curtains}

The typical fuel distribution of shopping malls in context of Bangladesh from existing literature, were considered in this present study [9]. The geometry analysed here was a section of Gulshan DCC market of Dhaka, Bangladesh as shown in Figure 1. This shopping mall was selected as its features resemble many other popular shopping malls in Bangladesh. The investigated clothing store was of $12 \mathrm{~m}^{2}$ floor area in front of the stair case with typical fuel distribution consists of three types of cloth displaying styles. The stacks of dark green colour represent the cloths in folding display with bulk density of $387.56 \mathrm{~kg} / \mathrm{m}^{3}$, the racks of lime green colour represent the cloths displayed with hanger in vertical orientation having bulk density of $77.52 \mathrm{~kg} / \mathrm{m}^{3}$, and the blue packs are exclusive cloths arranged side by side for maximum exposure having bulk density of $19.38 \mathrm{~kg} / \mathrm{m}^{3}$. The adjacent shops were also designed with fuel loads to assist 
the fire spreading, if happens. The fire source was at the furthest corner from the investigated shop door. An air curtain of $0.91 \mathrm{~m}$ length was placed at the investigated shop door at $2.13 \mathrm{~m}$ height from the floor. The air curtain's injection velocity was varied from $3 \mathrm{~m} / \mathrm{s}$ to $10 \mathrm{~m} / \mathrm{s}$ with $1 \mathrm{~m} / \mathrm{s}$ step size. The injection angle was varied from $0^{\circ}$ to $60^{\circ}$ with $15^{\circ}$ step size. The ratio of the distance between two flow channels with the flow channel width, defined as the pitch ratio, for a twin jet air curtain (a commercially available feature), was varied from 0 to 4 . The flow rate of the air curtain was varied from 1250 $\mathrm{m}^{3} / \mathrm{h}$ to $5000 \mathrm{~m}^{3} / \mathrm{h}$. Thus, a total of 24 different configurations were studied to find the optimum operating parameters for maximum effectiveness $\mathrm{E}$ of the air curtain compared to non-discharged condition. The schematic representation of the investigated air curtain parameters is shown in Figure 2.

The air curtain effectiveness $E$, is defined as the fraction of the exchange flow prevented by the air curtain compared to an unobstructed open door. The effectiveness $E$, was measured by the Eqs. (3), where, $Q_{a}$ and $Q_{o p e n}$ are the heat transfer through the door with the air curtain discharged and without the air curtain, respectively.

$$
E=1-\left(Q_{a} / Q_{\text {open }}\right)
$$

\subsection{Validation of Numerical Models}

The mesh independence was achieved by validating an ISO-9705 compatible room with clothing as fuel [10]. As suggested in the FDS user manual, a non-dimensional expression $D * / d x$ could be used to find the mesh resolved case. Here, $D^{*}$ is a characteristic fire diameter which can be expressed as in Eqs. (4) as follows,

$$
D^{*}=\left(\frac{\dot{Q}}{\rho_{\infty} c_{\infty} T_{\infty} \sqrt{g}}\right)^{\frac{2}{5}}
$$

Here, $\dot{Q}$ is the total heat release rate of the fire, $\rho_{\infty}, c_{\infty}, T_{\infty}$ are the ambient density, specific heat, and temperature. Study suggested, $D * / d x=10$ would be sufficient for a mesh resolved case [11]. Four values of $D * / d x, 4,10,16$ and 25 , were considered for mesh independence study. The summery of each case was provided in Table 1 . To observe the improvement in results by cost of resources, a dimensionless computation time was introduced, by dividing the computation time required for each case by the computation time required for the recommended case of $D * / d x=10$, (named moderate in this study). The results are presented in Figure 3 for the mesh independence study. From Figure 3 and Table 1, it was concluded that, the $D * / d x=10$ and $D * / d x=16$ cases, were within acceptable range in both resolution of result and demand of resources.

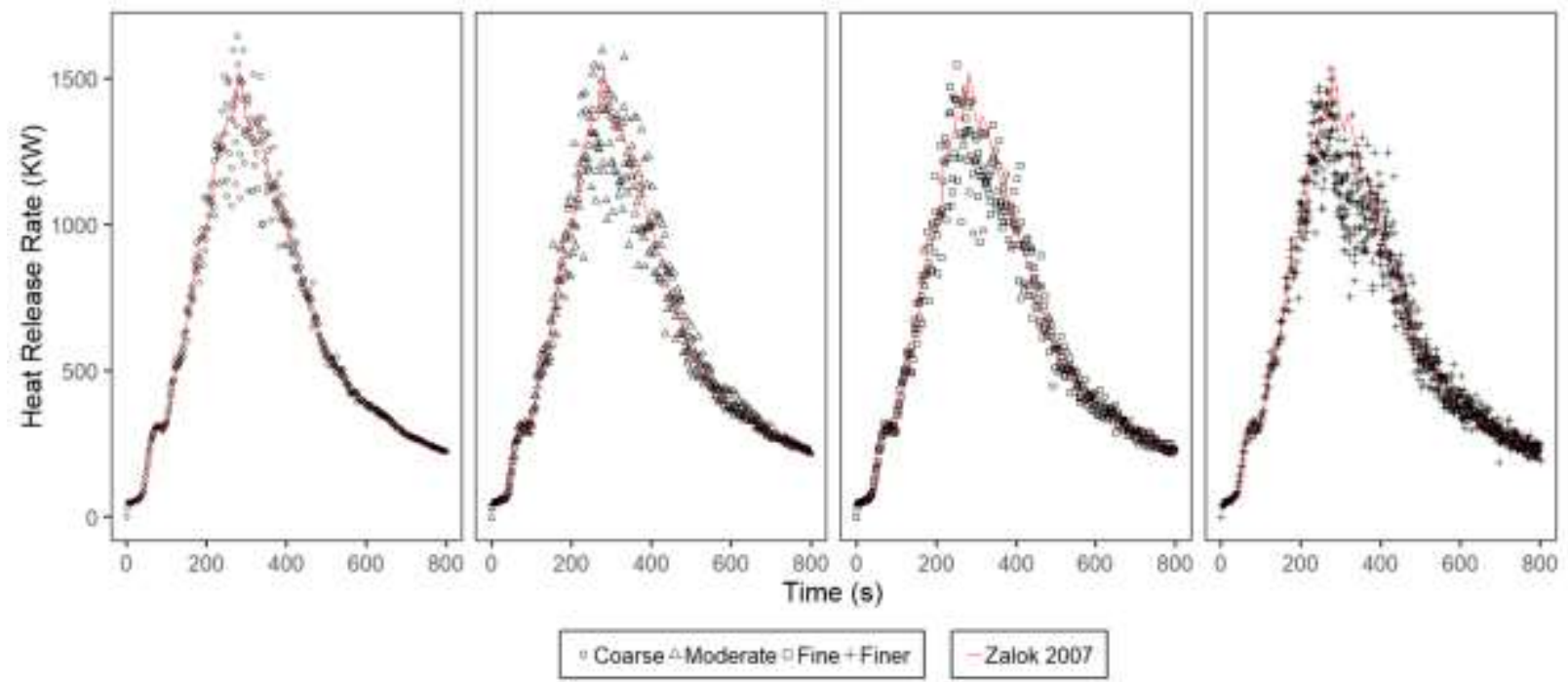

Fig. 3: Validation of Heat Release Rate (HRR) with Zalok et al. [10] and mesh sensitivity analysis. 
Table 1: Summary of the mesh sensitivity study.

\begin{tabular}{lllll}
\hline Mesh & $\boldsymbol{D}^{* / \boldsymbol{d} \boldsymbol{x}}$ & Cell Size (cm) & Elements & Time $^{\mathbf{1}}$ \\
\hline Coarse & 4 & 28.4 & 768 & 0.044 \\
Moderate & 10 & 11.36 & 18432 & 1 \\
Fine & 46 & 7.1 & 64800 & 4 \\
Finer & 25 & 4.5 & 218700 & 34.67 \\
\hline
\end{tabular}

${ }^{1}$ Dimensionless computation time [11]

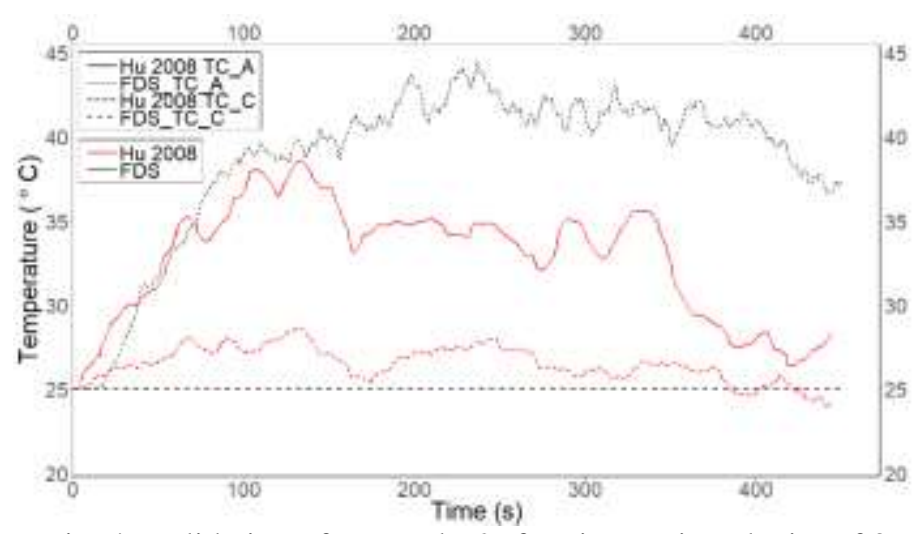

Fig. 4: Validation of Hu et al. [2] for air curtain velocity of 3 $\mathrm{m} / \mathrm{s}$.

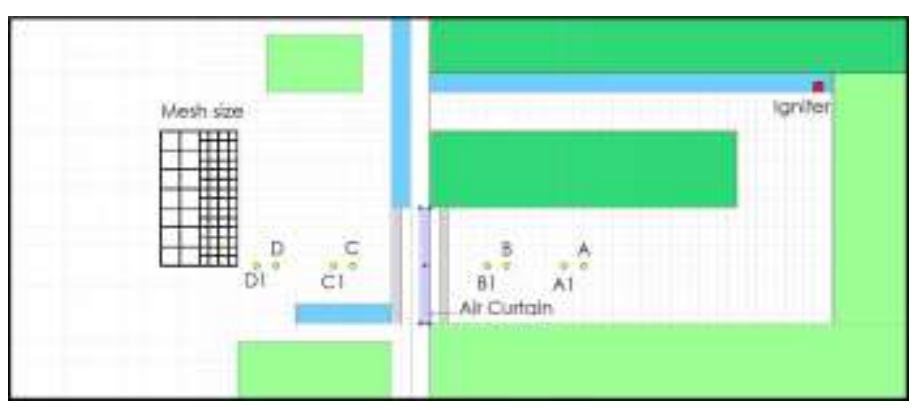

Fig. 5: Geometry and fuel distribution at the clothing store where fire originated.

The introduction of the air curtains in the FDS was validated with experimental work of Hu et al. [2]. Figure 4 represents the comparison of thermocouple temperature for before and after the air curtain, discharged at $3 \mathrm{~m} / \mathrm{s}$, for FDS simulation and experimental works. The trends of simulation results agree well with the experimental work, but the numerical values were somewhat offset. This may be caused by some assumptions that had to made, to conduct the simulation, due to lack of geometric information in the experimental report.

\subsection{Numerical Model}

Figure 5 represents the schematics of the clothing store where fire was considered to be originated. The store was chosen just in front of the staircase to mimic the worst-case scenario. The air curtain was installed at the door, as a vent of $7.62 \mathrm{~cm} \times 91.4 \mathrm{~cm}$ at a height of $2.134 \mathrm{~m}$. The fuel distribution and parameters were taken from a similar study [9]. The mesh size was $7.62 \times 7.62 \times 7.62 \mathrm{~cm}^{3}$ at the source and $15.24 \times 15.24 \times 15.24 \mathrm{~cm}^{3}$ at all other regions. The resulting $D * / d x$ were 15 at source and 7.5 at other regions (highlighted in figure). The investigated floor area was $12 \mathrm{~m}^{2}$ and there were 328,320 mesh elements. The temperature was measured at four places marked as A, B, C and D, at $2.9 \mathrm{~m}$ from the floor, as shown in Figure 5. The CO concentrations was measured at A1, B1, C1, and D1, at $2.9 \mathrm{~m}$ from the floor and $15.2 \mathrm{~cm}$ to the left of points $\mathrm{A}, \mathrm{B}, \mathrm{C}$, and $\mathrm{D}$, respectively.

\section{Results and Discussion}

In this study an air curtain at the door of clothing store of fire-origin was discharged to contain the fire and smoke propagation through that door. Figure 6 shows the temperature in Celsius scale for the thermocouples for positions A and D of Figure 5 with and without air curtain discharged, in function of simulation time in seconds. The horizontal line in Figure 6 represents $100^{\circ} \mathrm{C}$, the upper limit of human temperature tenability. The Figure 7 presents the $\mathrm{CO}$ concentration in ppm for gas devices placed at positions A1 and D1, with and without air curtain discharged in function of time in seconds. The horizontal line in Figure 7 represents 200 ppm CO concentration, exposure to this concentration for two to three hours will cause loss of judgment for the evacuees [12]. The discharge velocity was $10 \mathrm{~m} / \mathrm{s}$ and 


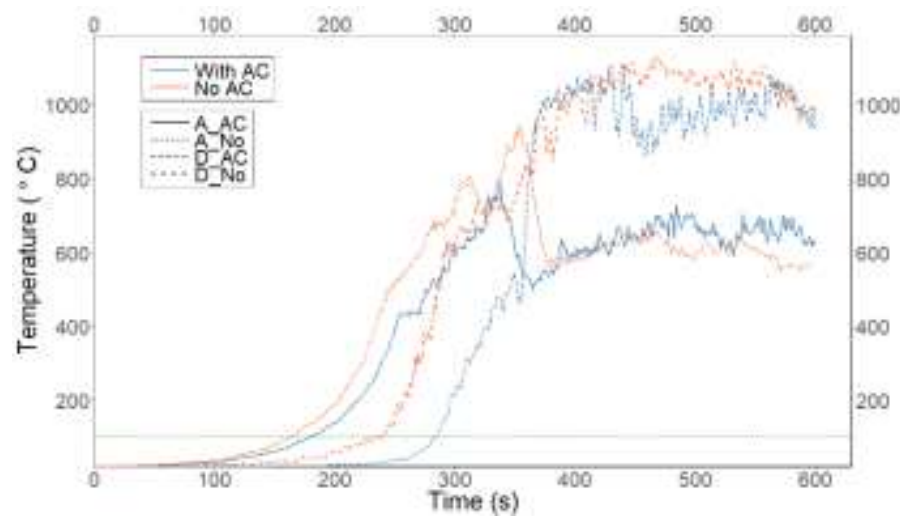

Fig. 6: Temperature at positions A (inside the fire source) and D (outside the fire source) for air curtain at discharged at $10 \mathrm{~m} / \mathrm{s}$, and non-discharged condition.

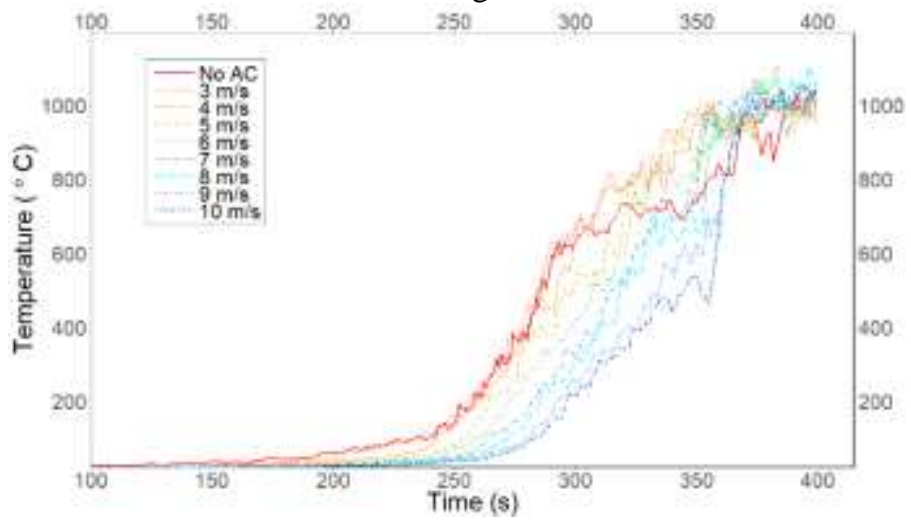

Fig. 8: Temperature at position D (outside the fire source) for air curtain discharged at velocities ranged from $3 \mathrm{~m} / \mathrm{s}$ to $10 \mathrm{~m} / \mathrm{s}$ with $1 \mathrm{~m} / \mathrm{s}$ step size.

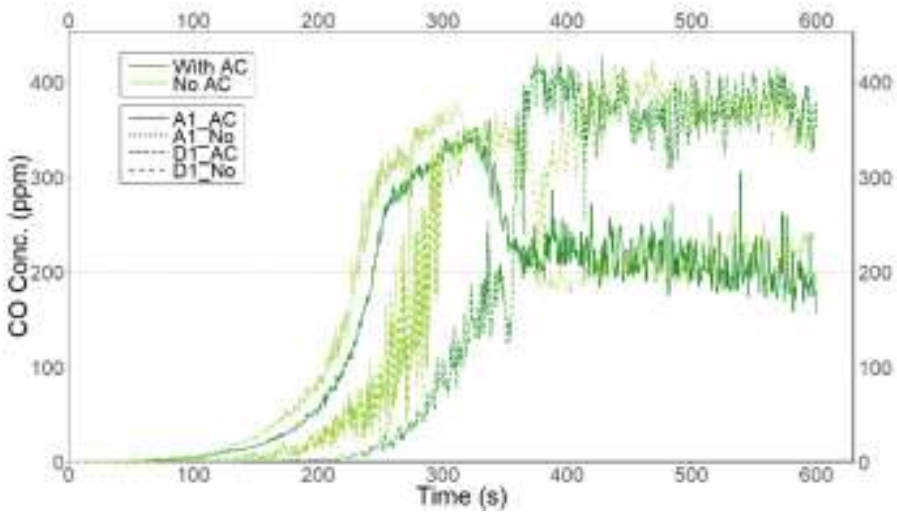

Fig. 7: CO concentration at positions A1 (inside the fire source) and D1 (outside the fire source) with air curtain (for discharge at $10 \mathrm{~m} / \mathrm{s}$ ) and without air curtain.

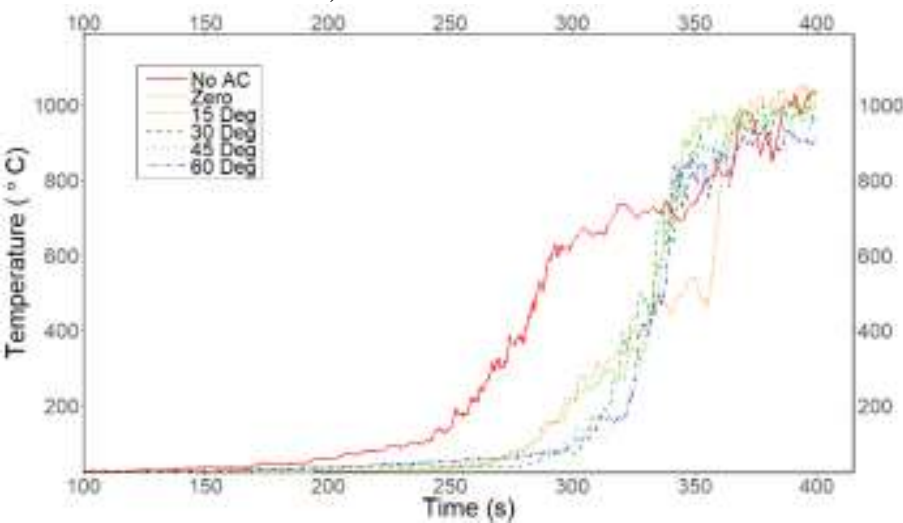

Fig. 9: Temperature at position D (outside the fire source) for air curtain discharged at $10 \mathrm{~m} / \mathrm{s}$ injection velocity at $0^{\circ}$ to $60^{\circ}$ injection angle with $15^{\circ}$ step size.

flow channel width were $7.62 \mathrm{~cm}$ for both cases. From Figure 6 and 7 it was evident that when air curtain was discharged, the rise of temperature and $\mathrm{CO}$ concentration to the lethal limits for the evacuees delayed for at least 50s. This increment in evacuation time could ensure over 10\% more safe evacuees for a typical shopping mall fire scenario in context of Bangladesh [13]. The temperature and $\mathrm{CO}$ concentration also decreased inside the source store for position A and A1, respectively, which was due to the circulation of air inside the store injected by the air curtain.

The effect of the variation of velocity on the temperature outside the source-store (thermocouple position D) for air velocity of $3 \mathrm{~m} / \mathrm{s}$ to $10 \mathrm{~m} / \mathrm{s}$ at a step size of $1 \mathrm{~m} / \mathrm{s}$ and for an air curtain of $7.6 \mathrm{~cm}$ flow channel width is shown in Figure 8 . As at low air curtain velocity the momentum ratio $R$ was low, air curtains with $3 \mathrm{~m} / \mathrm{s}$ and $4 \mathrm{~m} / \mathrm{s}$ injection velocity were not effective in confining the heat transfer. Increasing the air curtain velocity increase the momentum ratio, i.e., the air curtain injection velocity was able resist the smoke and heat flow through the door. At $5 \mathrm{~m} / \mathrm{s}$ injection velocity there was considerable temperature reduction at the position $\mathrm{D}$ and the reduction in temperature was proportional to the increase in injection velocity to $10 \mathrm{~m} / \mathrm{s}$, the highest velocity considered in this study.

The variation of temperature outside the source-store (at location D) with injection angle for a fixed flow velocity of 10 $\mathrm{m} / \mathrm{s}$ and $7.6 \mathrm{~cm}$ flow channel width of the air curtain are shown in Figure 9. The injection angle of the air curtain was varied from $0^{\circ}$ to $60^{\circ}$, inclined towards the fire source, with $15^{\circ}$ step size. Air curtain while injected at $15^{\circ}$ had no improvement over the $0^{\circ}$ injection angle, i.e., when air curtain injected vertically. The $30^{\circ}, 45^{\circ}$ and $60^{\circ}$ injection angle were more effective at delaying the temperature increase, for about $15 \mathrm{~s}$ for $30^{\circ}$, and $22 \mathrm{~s}$ for $45^{\circ}$ and $60^{\circ}$ injection angle. CO concentration at the same location D and for same operating conditions and the same variations of injection angles are presented in Figure 10. 


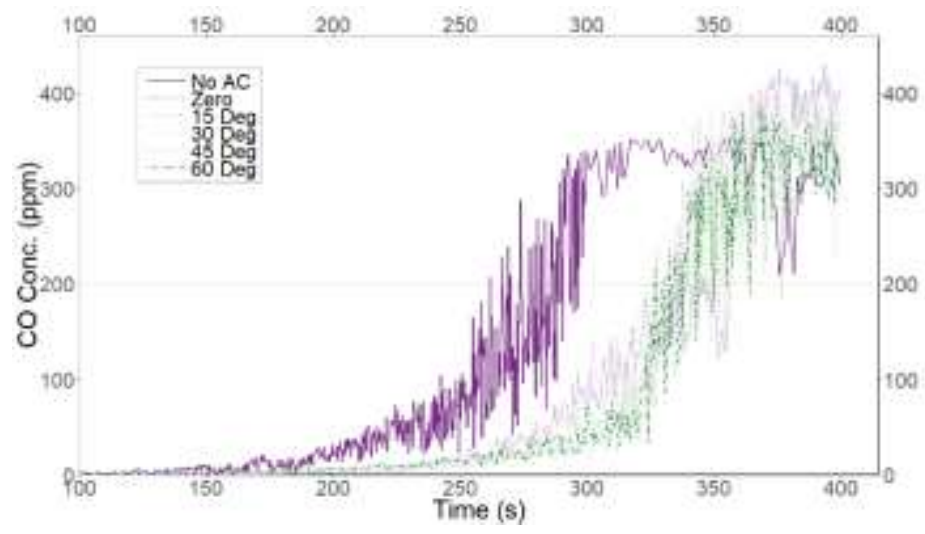

Fig. 10: CO concentration at position D1 (outside the fire source) for air curtain discharged at $10 \mathrm{~m} / \mathrm{s}$ injection velocity at $0^{\circ}$ to $60^{\circ}$ injection angle with $15^{\circ}$ step size.

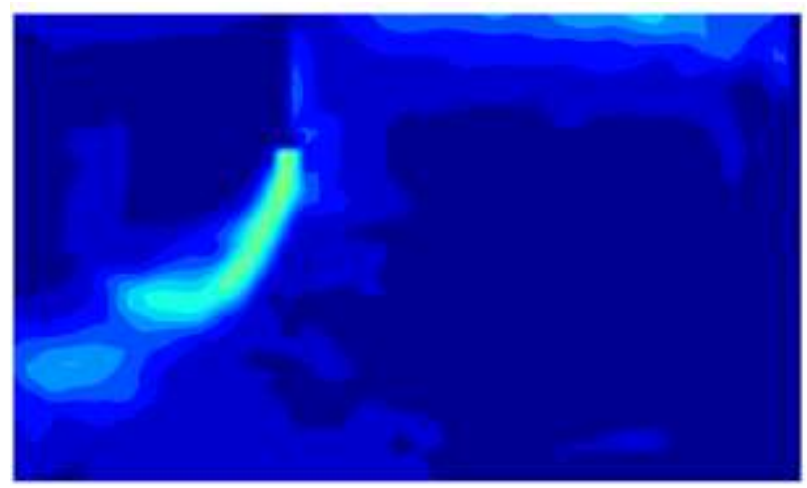

Fig. 12: Velocity contours for a 2D vertical plane AD, at the middle of the fire source store door with air curtain (for discharge at $10 \mathrm{~m} / \mathrm{s}$ ) at $250 \mathrm{~s}$.

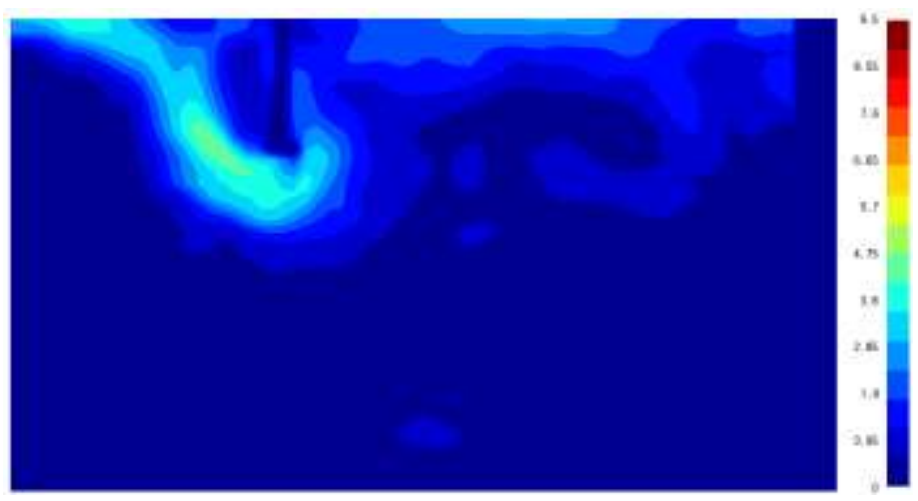

Fig. 11: Velocity contours for a 2D vertical plane AD, at the middle of the fire source store door without air curtain discharged at 250s.

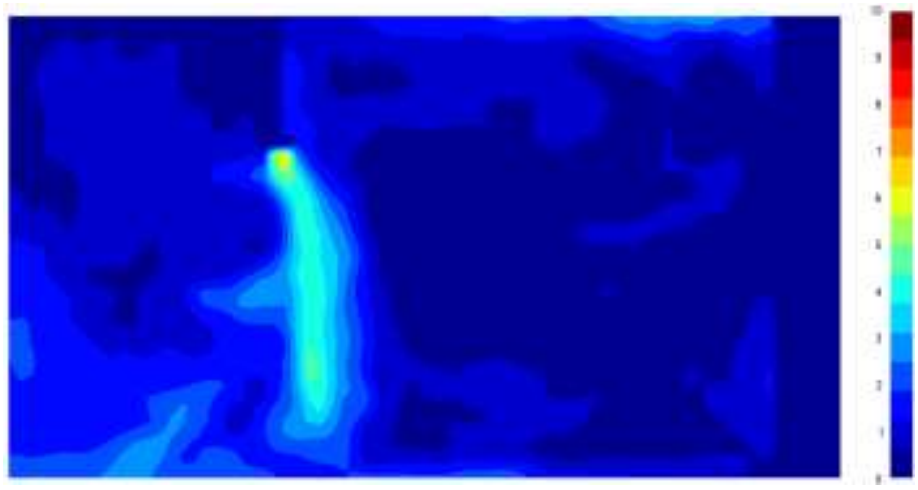

Fig. 13: Velocity contours for AD plane with the air curtain discharged at $10 \mathrm{~m} / \mathrm{s}$ injection velocity and $30^{\circ}$ injection angle at 250 s.

The $30^{\circ}, 45^{\circ}$ and $60^{\circ}$ injection angle were again effectively confined the CO particles i.e., the smoke, for increased amount of time than the $0^{\circ}$ and $15^{\circ}$ injection angle cases. Thus, varying the injection angle proved to be effective from $30^{\circ}$ to $60^{\circ}$ for both heat and smoke confinement. Figure 11 and 12 represents the velocity contours for a $2 \mathrm{D}$ vertical plane $\mathrm{AD}$, in the middle of fire source store door, intersecting the thermocouples at positions $\mathrm{A}, \mathrm{B}, \mathrm{C}$, and $\mathrm{D}$, without air curtain and with air curtain (for discharge at $10 \mathrm{~m} / \mathrm{s}$ ) at $250 \mathrm{~s}$ simulation time respectively.

From Figure 11, it was observed that, when air curtain was not discharged, the smoke escapes the room through the door and accumulated at the celling, agreeing well with the characteristics of smoke buoyancy. The fluids in bottom of the store remained nearly motionless. The velocity contours at $250 \mathrm{~s}$ with $10 \mathrm{~m} / \mathrm{s}$ air curtain velocity for the plane AD is shown in Figure 12. Due to the air curtain's discharge the circulation of fluids inside the store was visible in this Figure 12. Although the injection was vertical, at 250 s the air curtain's stream was pushed outwards by the increased fluid pressure. This increment in pressure was caused by the fluid expansion due to the heat release rate of the fire inside the store. The Figure 13 shows the velocity contours at $\mathrm{AD}$ plane, for $30^{\circ}$ injection angle configuration. As the velocity stream was inclined at first towards the fire source, and smoke accumulated at celling, the resulting interaction of the fluid forces made the stream nearly vertical at 250 s. Thus, even at 250 s the air curtain was able to retain the propagation of heat and smoke outside the store. 


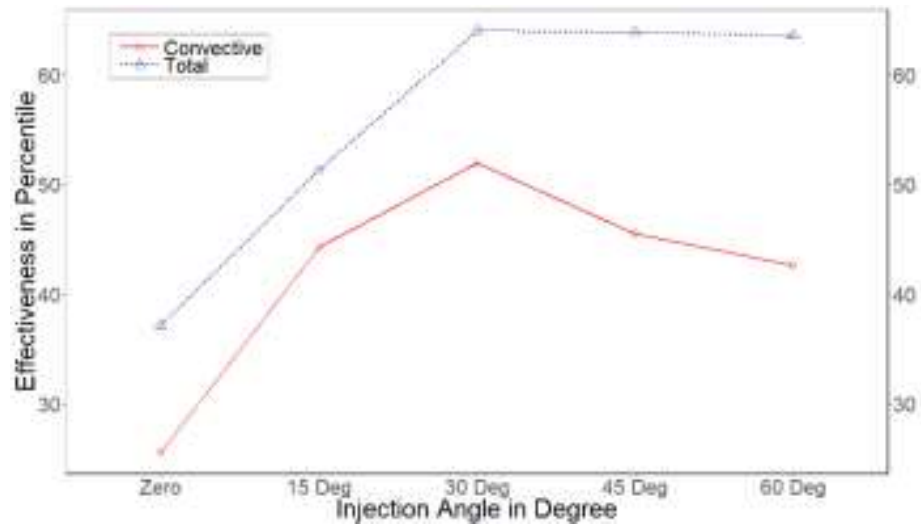

Fig. 14: The Total and Convective Effectiveness of air curtains at $7.62 \mathrm{~cm}$ flow channel width and $10 \mathrm{~m} / \mathrm{s}$ injection velocity in function of injection angle.

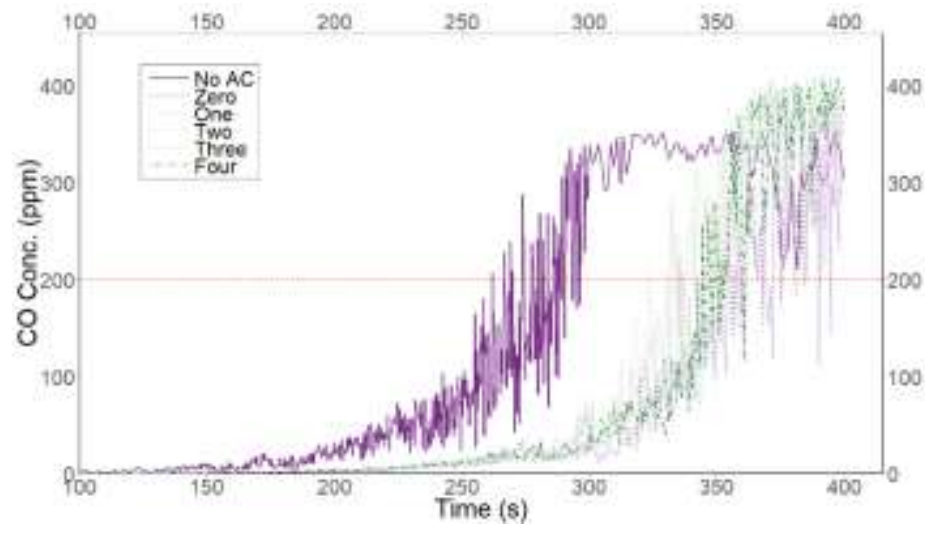

Fig. 16: CO concentration at position D1 (outside the fire source) for a $15.24 \mathrm{~cm}$ channel width air curtain at $10 \mathrm{~m} / \mathrm{s}$ injection velocity for $0,1,2,3$, and 4 pitch ratios.

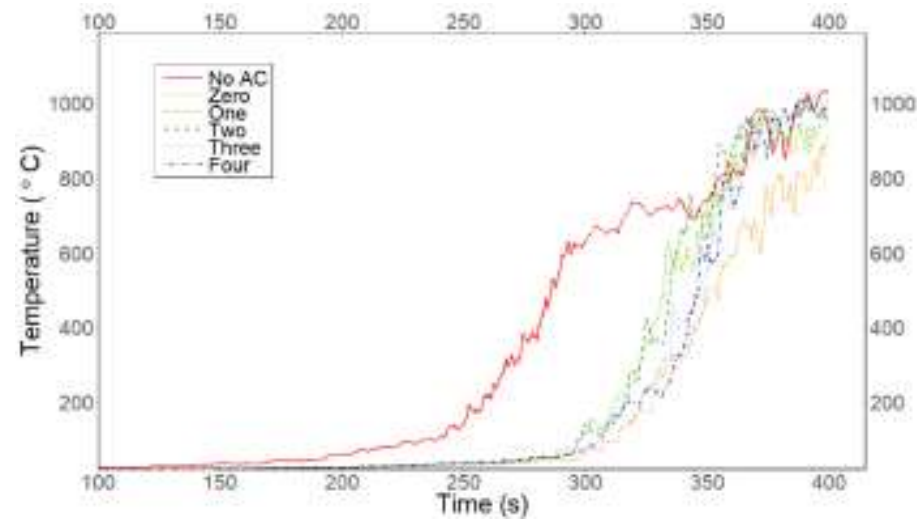

Fig. 15: Temperature at position $\mathrm{D}$ (outside the fire source) for a $15.24 \mathrm{~cm}$ channel width air curtain at $10 \mathrm{~m} / \mathrm{s}$ injection velocity for $0,1,2,3$, and 4 pitch ratios.

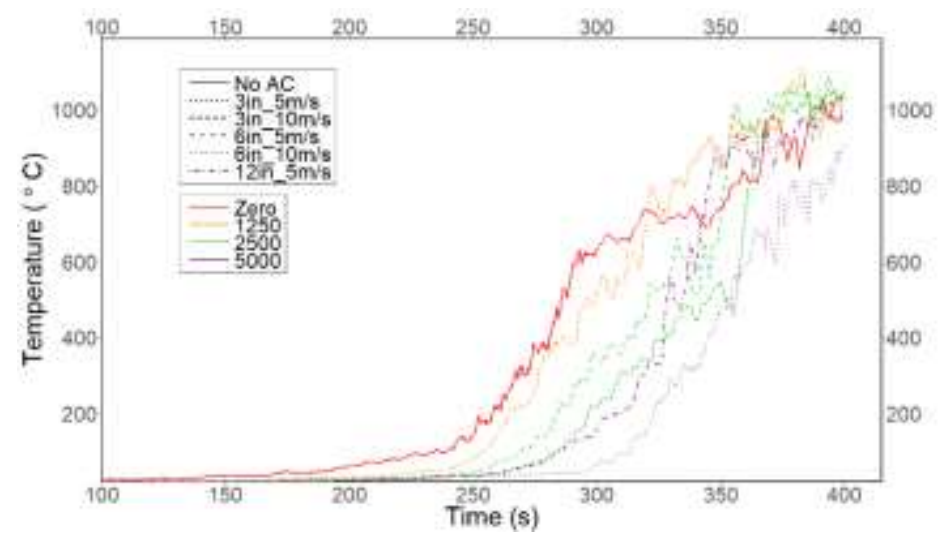

Fig. 17: Temperature at position D (outside the fire source) for air curtain discharged at 1250,2500 and $5000 \mathrm{~m}^{3} / \mathrm{h}$ at different channel width and injection velocity.

To observe the effect of the angle variations more explicitly, the effectiveness $E$ was calculated for the injection angles. The convective heat flux and the radiative heat flux was calculated at the door of the source store with and without the air curtain.

Although air curtain, discharged at $10 \mathrm{~m} / \mathrm{s}$, was effective in confining the fire and smoke inside the store for about 50s more than non-discharged case, it was unable to control the fire at the flashover phase. The flashover defined as the phase when fire spreads rapidly throughout the space, resulting total involvement of the enclosed area. Due to the extreme fluid pressure at this phase, air curtain failed to confine the spread of fire, and fire came out of the store to the hallway. Including flashover phase in effectiveness calculation for air curtain will greatly overshadow air curtain's contribution before flashover phase.

Thus, the effectiveness was evaluated up to 246s, when flashover was observed for the non-discharged air curtain configuration. Both the total effectiveness and the convective-only effectiveness of air curtains for $7.62 \mathrm{~cm}$ flow channel width and $10 \mathrm{~m} / \mathrm{s}$ injection velocity are calculated and presented in function of injection angle in Figure 14 . The $30^{\circ}$ injection angle case provides the best total and convective only effectiveness among the investigated injection angles. The total effectiveness was about $64 \%$ and convective-only effectiveness was about $51 \%$ for the $30^{\circ}$ injection angle configuration. Thus, $30^{\circ}$ was considered the optimum injection angle for air curtain. The temperature at position $\mathrm{D}$, and $\mathrm{CO}$ concentration 
at position D1, for air curtains in twin jet configuration in $0,1,2,3$, and 4 pitch ratios, are plotted in function of time in Figure 15 and Figure 16, respectively. There were two $7.62 \mathrm{~cm}$ flow channels and the injection velocities were 10 $\mathrm{m} / \mathrm{s}$ at $0^{\circ}$ injection angle. From both of the Figure 15 and 16 it was evident that the twin jet configuration was less effective at sealing the heat and smoke transfer at all pith ratios when compared to the zero-pitch ratio, i.e., at single jet configuration.

The temperature at position D for air curtains at different flow channel width and velocities at same flow rate for three different flow rates are shown in Figure 17. The increase in velocity reducing the channel width for a certain flow rate was seen to be beneficial for the heat confinement. The sealing performance of an air curtain with $15.24 \mathrm{~cm}$ channel width, at $10 \mathrm{~m} / \mathrm{s}$ injection velocity and $30^{\circ}$ injection angle at the door of fire source store was investigated. The parameters for this air curtain were taken as the best performing ones, from the previous results. The effects of the different air curtain parameters were found additive. This air curtain configuration had an effectiveness of $72 \%$ and was the highest effective configuration among all the investigated configurations. This improvement in sealing the heat and smoke inside the fire source store could ensure $16 \%$ more safe evacuees for a typical fire incident in context of Bangladesh.

\section{Conclusion}

Air curtains were investigated numerically as an effective thermal and aerosol barrier against high pressure and velocity gradients generated by a typical shopping mall fire. Eight injection velocity, five injection angle and three flow rates of the air curtain, with five pitch ratios of the flow channel were investigated to find the optimum operating condition to ensure maximum sealing of the heat and smoke. Results suggested, an off the shelf air curtain placed at shop door could provide 37\% effectiveness in sealing the heat and mass transfer, which might ensure at least 10\% more safe evacuees in case of a fire hazard. The aerodynamic sealing was improved when the injection velocity and injection angle were increased. The twin jet design had no improvement over the single jet design for the same flow channel width. Using optimum air curtain parameters, a maximum of $72 \%$ air curtain effectiveness and $16 \%$ increase in safe evacuees was observed, for a single jet air curtain of $15.24 \mathrm{~cm}$ flow width, at $10 \mathrm{~m} / \mathrm{s}$ injection velocity and $30^{\circ}$ injection angle. The influence of the momentum ratio $R$ on the effectiveness $E$, was not included in this present study, which is expected to be pursued in subsequent investigations.

\section{Acknowledgements}

The authors would like to express their gratitude to Thunderhead Engineering for the academic license of PyroSim software.

\section{Nomenclature}

$\begin{array}{ll}E & \text { Air curtain effectiveness }(\%) \\ R & \text { Air curtain momentum ratio } \\ D^{*} & \text { Characteristic fire diameter } \\ \dot{Q} & \text { Total heat release rate of the fire }(\mathrm{kW}) \\ Q & \text { Heat transfer }(\mathrm{kW}) \\ c & \text { Specific heat }(\mathrm{kJ} / \mathrm{kg}-\mathrm{K}) \\ k & \text { Thermal conductivity }(\mathrm{W} /(\mathrm{m}-\mathrm{K})) \\ u & \text { Velocity in the } x \text { direction }(\mathrm{m} / \mathrm{s}) \\ T & \text { Temperature }(\mathrm{K}) \\ g & \text { Acceleration due to gravity }\left(\mathrm{m} / \mathrm{s}^{2}\right) \\ \mathrm{Pr} & \text { Prandtl number } \\ \mathrm{Sc} & \text { Schmidt number }\end{array}$

\author{
Greek symbols \\ $\rho \quad$ Density $\left(\mathrm{kg} / \mathrm{m}^{3}\right)$ \\ $\mu \quad$ Absolute viscosity $(\mathrm{kg} /(\mathrm{m}-\mathrm{s}))$ \\ $\tau \quad$ Shear stress $(\mathrm{Pa})$
}

$\begin{array}{ll}\text { Subscripts } & \\ \infty & \text { Ambient condition } \\ t & \text { Turbulent } \\ b & \text { Bulk } \\ s g s & \text { Subgrid-scale } \\ a & \text { With air curtain } \\ \text { open } & \text { Without air curtain }\end{array}$




\section{References}

[1] R. Besserre and P. Delort, "Recent studies prove that the main cause of death during urban res is poisoning by smoke," Urgences Medicales, vol. 2, no. 16, pp. 77-80, 1997.

[2] L.H. Hu, J.W. Zhou, R. Huo, W. Peng, and H.B. Wang, "Confinement of fire-induced smoke and carbon monoxide transportation by air curtain in channels," Journal of hazardous materials, vol. 156, no. 1-3, pp. 327-334, 2008.

[3] L. Guyonnaud, C. Solliec, M. Dufresne de Virel, and C. Rey, "Design of air curtains used for area confinement in tunnels," Experiments in Fluids, vol. 28, no. 4, pp. 377-384, 2000.

[4] Y.C. Shih, A.S. Yang, and C.W. Lu, "Using air curtain to control pollutant spreading for emergency management in a cleanroom," Building and Environment, vol. 46, no. 5, pp. 1104-1114, 2011.

[5] J.C. Elicer-Cortés, R. Demarco, A. Valencia, and M. Pavageau, "Heat confinement in tunnels between two doublestream twinjet air curtains," International Communications in Heat and Mass Transfer, vol. 36, no. 5, pp. 438-444, 2009.

[6] N. Luo, A. Li, R. Gao, Z. Tian, W. Zhang, S. Mei, L. Feng, and P. Ma, "An experiment and simulation of smoke confinement and exhaust efficiency utilizing a modified Opposite Double-Jet Air Curtain," Safety science, vol. 55, pp. 17-25, 2013.

[7] L.X. Yu, F. Liu, T. Beji, M.C. Weng, and B. Merci, "Experimental study of the effectiveness of air curtains of variable width and injection angle to block fire-induced smoke in a tunnel configuration," International Journal of Thermal Sciences, vol. 134, pp. 13-26, 2018.

[8] M.J.B. Alam, and G.N. Baroi, "Fire hazard categorization and risk assessment for Dhaka city in GIS framework," J. Civ. Eng.(IEB), vol. 32, no. 1, pp. 35-45, 2004.

[9] M.A.M.S. Shoshe and M.A. Rahman, "Spread and Propagation of Generic Shopping Mall Fire of Bangladesh Under Different Scenarios," in Proceedings of International Conference on Disaster Risk Management, Dhaka, Bangladesh, 2019, pp. 641-648.

[10] E. Zalok and G. Hadjisophocleous, "Characterizing of design fires for clothing stores," in Proceedings of the 5th International Seminar on Fire and Explosion Hazards, Edinburgh, UK, 2007, pp. 328-337.

[11] R.J. McDermott, G.P. Forney, K. McGrattan, and W.E Mell, "Fire Dynamics Simulator Version 6: Complex Geometry, Embedded Meshes, and Quality Assessment," in Proceedings of the V European Conference on Computational Fluid Dynamics ECCOMAS CFD 2010, Lisbon, Portugal, 2010.

[12] M. Goldstein, "Carbon Monoxide Poisoning," Journal of Emergency Nursing, vol. 34, pp. 538-542, 2008.

[13] E.A. Khan, M.A. Ahmed, E.H. Khan, and S.C. Majumder, "Fire Emergency Evacuation Simulation of a shopping mall using Fire Dynamic Simulator (FDS)," Journal of Chemical Engineering, vol. 30, no. 1, pp. 32-36, 2017. 